\title{
Treatment of a cutaneous odontogenic sinus tract of endodontic origin: A case report
}

\author{
Beril Kıvılcım, Muammer Kıvanç Aksoy, Seçkin Dindar, Beliz Özel \\ Department of Endodontics, Istanbul University Faculty of Dentistry, Istanbul, Turkey
}

\begin{abstract}
Extraoral sinus tracts of endodontic origin are often misdiagnosed. The presence of these formations on the skin and, in some cases, their location at a distance from the odontogenic source lead to difficulties in the identification of these infections. It is important for these infections to be correctly diagnosed and separated from other lesions by dentists to prevent patients from being exposed to unnecessary medications and treatments. Root canal treatment of related tooth provides success in many cases of extraoral sinus tract of endodontic origin. The following case presents the management of a cutaneous sinus tract originating from a mandibular central incisor by conventional endodontic treatment.
\end{abstract}

Keywords: Cutaneous sinus tract; endodontic therapy; extraoral sinus tract; odontogenic.

A sinus tract is a condition in which a particular area of infection spreads along the epithelial surface leading to the skin surface or body cavity. The most common reason of a cutaneous sinus tract in the head and neck regions is chronic dental infections. ${ }^{[1]}$

These lesions may occur away from the odontogenic source or anywhere on the skin. Therefore, they are often misdiagnosed with localized skin infections, ingrown hair, osteomyelitis, tuberculosis, neoplasms, and actinomycosis. ${ }^{[2,3]}$

Common areas where these occurrences are most frequently seen are the mandibular angle, submental area, chin, and cheeks. Approximately $80 \%-87 \%$ of the cases originate from the mandibular teeth. Usually, there is no symptom in the related tooth. ${ }^{[4]}$

Odontogenic extraoral sinus tracts are often misdiagnosed. Most of these patients are examined by other doctors until they are referred to a dentist. The condition is often tried to be treated with surgical operations, long-term antibiotic treatment, and radiotherapy. However a large portion of these occurrences can be treated with endodontic treatment only, without a need for a surgical intervention. ${ }^{[4]}$

The following case presents the management of a cutaneous sinus tract originating from a mandibular central incisor by conventional endodontic treatment.

\section{Case report}

A 28-year-old woman was referred to the Department of Endodontics with complaints of mobility, percussion, and palpation (Fig. la-c). Her medical and dental history revealed no trauma, caries or surgery along the region. During inspection, an extraoral sinus tract was observed at the affected area. Vitality was negative for the mandibular left central incisor. Radiographic examination revealed a large radiolucency in the peripheral bone of the related tooth.

Correspondence: Dr. Beril Kıvılcım. İstanbul Üniversitesi Diş Hekimliği Fakültesi,

Endodonti Anabilim Dalı, İstanbul, Turkey.

Tel: +90 212 - 4142020 e-mail: berilkivilcim@gmail.com

Submitted: April 09, 2018 Accepted: May 31, 2018 

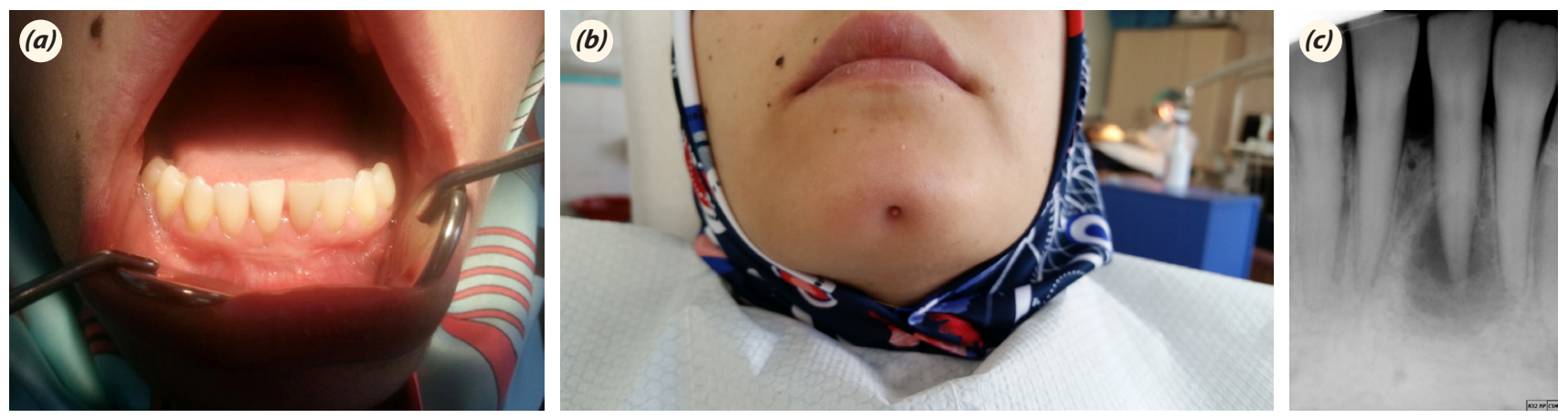

Fig. 1. (a-c) Pre-operative clinical and radiographics images of the patient.

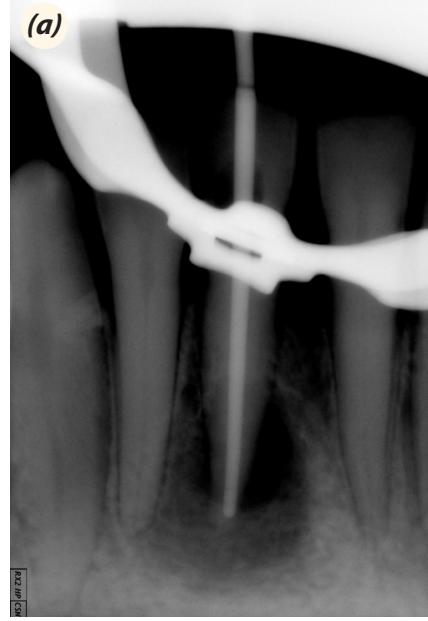

(b)
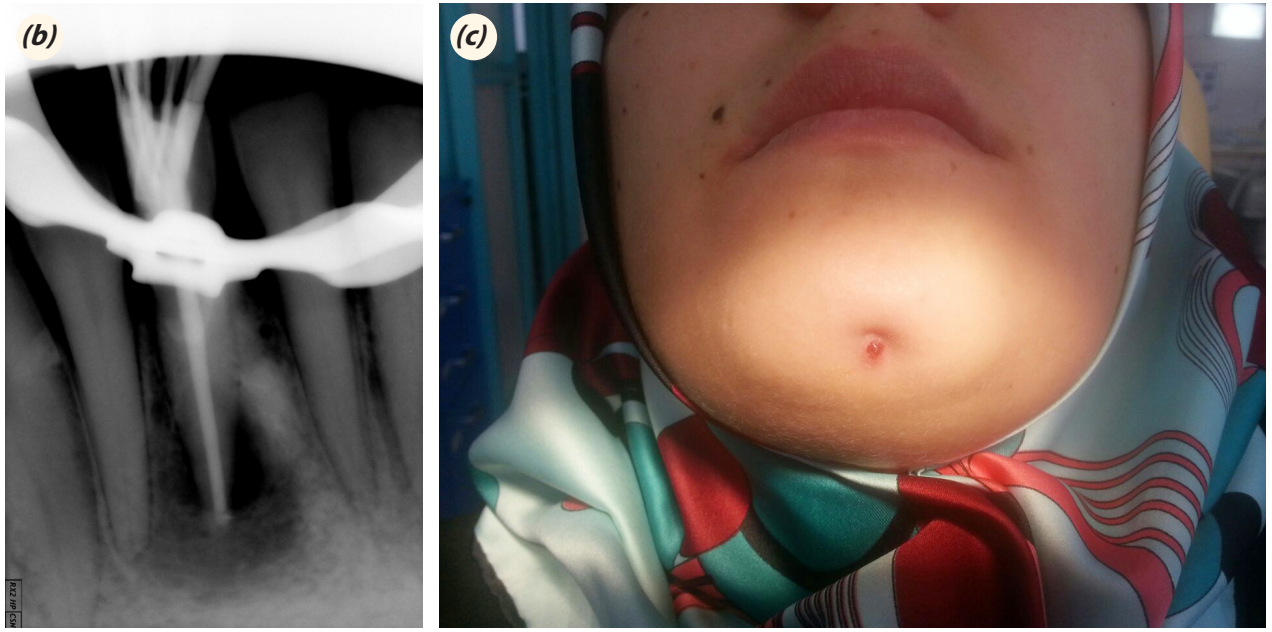

Fig. 2. (a-c) Radiographic and extraoral images taken on the second appointment.
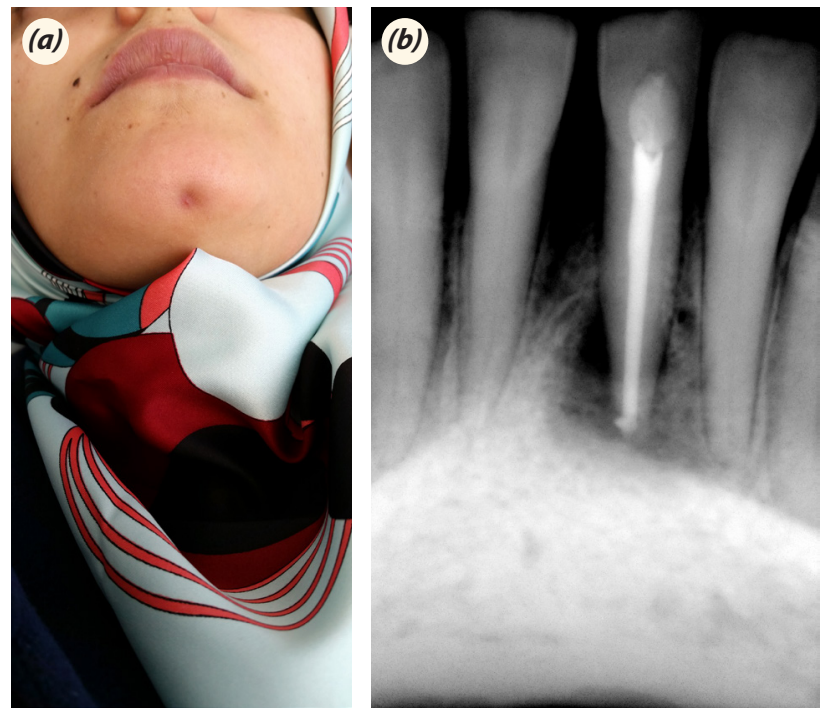

Fig. 3. (a, b) Clinical and radiographic images taken on 4 month control.

Root canal preparation was completed with stainless steel hand files, and master apical size was determined to be \#40. With each file change, root canal was irrigated with $2 \mathrm{cc}$ of $5.25 \%$ sodium hypochlorite $(\mathrm{NaOCl})$. For
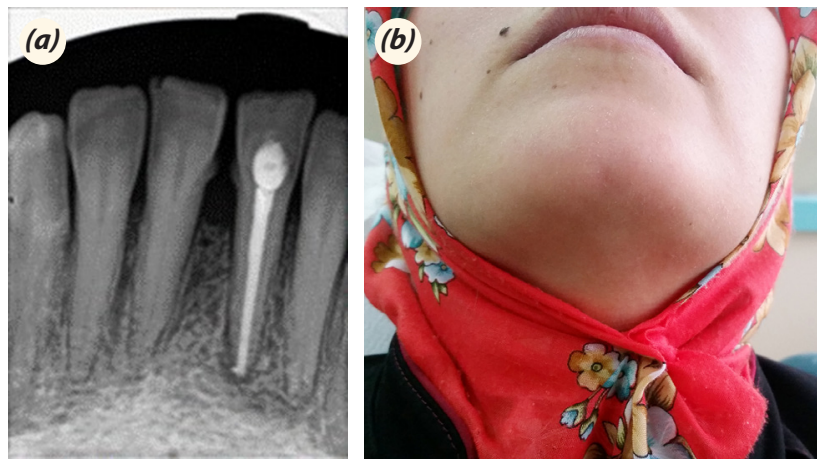

Fig. 4. (a, b) Clinical and radiographic images of follow-up after 2 years.

the final irrigation, $2 \mathrm{cc}$ of $5.25 \% \mathrm{NaOCl}$ followed by $5 \mathrm{cc}$ of $17 \%$ EDTA and $5 \mathrm{cc}$ of saline. Calcium hydroxide $\left(\mathrm{CaOH}_{2}\right)$ was placed inside as intracanal medication, and the patient was appointed 2 weeks later. The root canal treatment was completed with cold lateral condensation (Fig. 2a-c).

Sinus tract was closed in 4-month control (Fig. 3a, b). A 2-year follow-up confirmed that the sinus tract had completely healed (Fig. 4a, b), and radiography revealed bone formation. 


\section{Discussion}

To be able to have an invasive approach in the treatment of these formations, it is necessary to determine whether the source is odontogenic or non-odontogenic prior to the treatment. ${ }^{[5]}$ Because the cutaneous sinus tracts may occur at a distant point from the infection source, all teeth alongside the relevant region should be clinically and radiographically examined. Therefore, the existence of a devital tooth should be investigated by vitalometric examination, and any periapical lesion presence should be investigated by panoramic and/or periapical X-rays. If possible, a radiograph captured from the sinus tract by inserting a gutta-percha con into the sinus tract will show a direct odontogenic source. ${ }^{[6]}$

Antibiotic administration in these cases temporarily allows exudate drainage to be discontinued, but unless the infection is removed, the presence of this formation continues, and exudate drainage can be intermittently observed.

In this case, $\mathrm{CaOH}_{2}$ was kept in the root canal for 2 weeks. The exudate drainage was interrupted, and healing was observed. In the case report published by Heling et al., ${ }^{[3]} 1.5 \% \mathrm{NaOCl}$ was used during chemomechanical shaping, and $\mathrm{CaOH}_{2}$ was stored in the root canal for 1 week. No such improvement was observed after this treatment, and periapical surgery was performed. The failure of their case can be attributed to the fact that $\mathrm{CaOH}_{2}$ was not kept in the root canal for a sufficient time or that $\mathrm{Na}$ $\mathrm{OCl}$ administration at a low concentration failed to provide sufficient bacterial elimination. In another case report published by Soares et al., $5.25 \% \mathrm{NaOCl}$ was used during root canal treatment, and the $\mathrm{CaOH}_{2}$ medicament was stored in the root canal to be renewed every month for 4 months. After they observed healing in the periapical tissues, they completed the root canal treatment without any surgical interventions. ${ }^{[7]}$ Similar to our case, Sotiropoulus et al. kept $\mathrm{CaOH}_{2}$ in the root canal for 3 weeks and filled the root canal after achieving a visible improvement. ${ }^{[6]}$ Af- ter a successful treatment, the onset of healing is expected within a few weeks. Prior to the next step, it is important to provide adequate time for observing any healing. ${ }^{[8]}$

\section{Conclusion}

Extraoral sinus tracts of endodontic origins can be successfully healed by non-surgical root canal treatment. It is important to make a careful examination and consultation when necessary to avoid unnecessary treatments.

Conflict of interest: None declared.

\section{References}

1. Sammut S, Malden N, Lopes V. Facial cutaneous sinuses of dental origin - a diagnostic challenge. Brit Dent J 2013;215:555-8. [CrossRef]

2. Bai J, Ji AP, Huang MW. Submental cutaneous sinus tract of mandibular second molar origin. Int Endod J 2014;47:1185-91. [CrossRef]

3. Heling I, Rotstein I. A persistent oronasal sinus tract of endodontic origin. J Endod 1989;15:132-4. [CrossRef]

4. Chen K, Liang Y, Xiong H. Diagnosis and treatment of odontogenic cutaneous sinus tracts in an 11-year-old boy: a case report. Medicine (Baltimore) 2016;95:e3662. [CrossRef]

5. Özdemir A, Güven G, Dilsiz A, Şençimen M. Diagnosis and treatment of mandibular extraoral sinus of periodontal origin in a 9-year-old boy: a case report. J Indian Soc Pedod Prevent Dent 2008;26 Suppl 2:76-8.

6. Sotiropoulos GG, Farmakis ET. Diagnosis and conservative treatment of extraoral submental sinus tract of endodontic origin: a case report. J Clin Diagn Res 2014;8:ZD10-1. [CrossRef]

7. Soares JA, de Carvalho FB, Pappen FG, Araújo GS, de Pontes Lima RK, Rodrigues VM, et al. Conservative treatment of patients with periapical lesions associated with extraoral sinus tracts. Aust Endod J 2007;33:131-5. [CrossRef]

8. Giménez-García R, Martinez-Vera F, Fuentes-Vera L. Cutaneous sinus tracts of odontogenic origin: two case reports. J Am Board Fam Med 2015;28:838-40. [CrossRef] 